Journal of Universal Mathematics

VOL.2 No.1 PP.36-41 (2019)

ISSN-2618-5660

\title{
ON THE DETERMINATION STUDENTS' APTITUDE USING INTUITIONISTIC FUZZY LOGIC
}

\author{
FERIDE TUĞRUL, MEHMET ÇİTİL, AND SEBAHATTIN BALCI
}

\begin{abstract}
In this paper, we have proposed an application of intuitionistic fuzzy set in high school determination using normalized hamming distance method. The purpose of this paper is to ensure that the high schools select the best students according to the quotas.Intuitionistic fuzzy set is lucrative model in order to detail uncertainty involved in decision making. In this paper; enroll of students to the high schools has been intuitionally determined according to students' pilot test score. Normalized hamming distance method has been utilized in order to measure the distance between the student and each high school. The schools, in which each of the students have enrolled, have determined via normalized hamming distance method depending on examination that is performed for transition to high school education. Solution has been stated by measuring the smallest distance between the student and each school.
\end{abstract}

\section{INTRODUCTION}

The notion of fuzzy logic was firstly defined by L.A.Zadeh in 1965 [1].The membership function of an element to a fuzzy set is a value between zero and one, the non-membership function of an element to a fuzzy set is equal to 1 minus the membership degree in fuzzy set theory. Then,Intuitionistic fuzzy sets (shortly IFS) were defined by K.Atanassov in 1986 [2]. Intuitionistic fuzzy sets form a generalization of the notion of fuzzy sets. In intuitionistic fuzzy set theory, sum of the membership function and the non-membership function is a value between zero and one. The hesitation degree is defined as 1 minus the sum of membership and non-membership degrees respectively in intuitionistic fuzzy sets. In fuzzy set theory, the hesitation degree is zero since sum of the membership function and the non-membership function is 1.The intuitionistic fuzzy set theory is useful in various application areas, such as algebraic structures,robotics, control systems, agriculture areas, computer, irrigation, economy and various engineering fields. The knowledge and semantic representation of intuitionistic fuzzy set become more meaningful,resourceful and applicaple since it includes the degree of membership, the degree of non-membership and the hesitation margin [3]. Szmidt and Kacprzyk have showed that intuitionistic fuzzy sets are pretty useful in situations when description of a problem by a

Date: Review December 27, 2018, accepted January 17, 2019.

2000 Mathematics Subject Classification. 03E72.

Key words and phrases. Intuitionistic fuzzy sets, High school determination, Distance measure,Normalized hamming distance method. 
linguistic variable given in terms of a membership function only seems too rough [6]. Due to the flexibility of intuitionistic fuzzy set in handling uncertainty, it is a tool for a more human consistent reasoning under imperfectly defined facts and imprecise knowledge [7].

Various applications of intuitionistic fuzzy set have been carried out through distance measures approach.Many researchers have explored various applications of intuitionistic fuzzy set such as medical diagnosis,medical application,career determination,real life situations,education, choice [6][7][8][9][10][11][12] [14].

The main purpose is to find the best and the most suitable of the materials needed to solve a problem. These materials could be a machine in some cases, a human in some cases, etc. The purpose of this paper is to ensure that the high schools select the best students according to the quotas. In this paper; enroll of students to the high schools (in Table 1) has been intuitionally determined according to students' pilot test score (in Table 2). We proposed an application of intuitionistic fuzzy set in school determination via normalized hamming distance method. Normalized hamming distance method was utilized in order to measure the distance between each student and each school.The schools in which each of the students has enrolled were determined via normalized hamming distance method depending upon examination that is performed for transition to high school education. Solution is determined by measuring the smallest distance between each student and each school.The aim of this paper is to interpret the relationship between the student's pilot tests and the official exam.

For this paper; high schools in Kahramanmaraş city in Turkey have been researched.There is an exam in Turkey performed for transition to high school education. Each of the students has been enrolled in each high school taking their examination scores into account. Students' school achievement scores do not have a huge impact on their examination scores. Therefore; their school achievement scores have been accepted as fixed. Besides; success score of the schools has been accepted fixed. While searching database which is used in this paper; socio-economic status of students,student psychology,success of schools, teacher factor,order of preference,different city preference of students are ignored. As factors such as success of student, examination difficulty vary every year, these data will show variability for every year.In this paper; each high school base point has been calculated depending on student examination score(over 100 marks total). This research has utilized offical data that were obtained from the Ministry of Education. Approximately 7000 students have been searched for 2016 - 2017 academic year. Afterwards, some students who were randomly selected have been searched depending on scores of the exam.

We have used intuitionistic fuzzy sets as a tool since it incorporates the membership degree(the marks of the questions that have been correctly answered by the student, the non-membership degree(the marks of the questions that have been wrongly answered by the student) and the hesitation degree(the marks of the questions that are free from any answer). Solution has been assumed by measuring the smallest distance between each student and each school via normalized hamming distance method. In solution; high school has been intuitionally assumed. 


\section{PRELIMINARIES}

Definition 2.1. [1] Let $X$ be a nonempty set. A fuzzy set $A$ drawn from $X$ is defined as $A=\left\{\left\langle x, \mu_{A}(x)\right\rangle \mid x \in X\right\}$, where $\mu_{A}(x): X \rightarrow[0,1]$ is the membership function of the fuzzy set $A$.

Definition 2.2. [2][3] Let $X$ be a nonempty set. An intuitionistic fuzzy set $A$ in $X$ is an object having the form

$$
A=\left\{\left\langle x, \mu_{A}(x), \nu_{A}(x)\right\rangle \mid x \in X\right\},
$$

where the function

$$
\mu_{A}(x), \nu_{A}(x): X \rightarrow[0,1]
$$

define respectively, the degree of membership and degree of nonmembership of the element $x \in X$, to the set $A$, which is a subset of $X$, and for every element $x \in X$,

$$
0 \leq \mu_{A}(x)+\nu_{A}(x) \leq 1 .
$$

According to Fuzzy Set Theory, if the membership degree of an element $x$ is $\mu(x)$, if the nonmembership degree of an element $x$ is $1-\mu(x)$

Furthermore, we have

$$
\pi_{A}(x)=1-\mu_{A}(x)-\nu_{A}(x)
$$

called the intuitionistic fuzzy set index or hesitation on margin of $x$ in $A . \pi_{A}(x)$ is degree of indeterminacy of $x \in X$ to the IFS A and $\pi_{A}(x) \in[0,1]$ i.e.,

$$
\pi_{A}: X \rightarrow[0,1]
$$

for every $x \in X . \pi_{A}(x)$ expresses the lack of knowledge of whether $x$ belongs to IFS $A$ or not.

In the theory of fuzzy sets [13] two different types of distances are defined,generated from the following metric

$$
m_{A}(x, y)=\left|\mu_{A}(x)-\mu_{A}(y)\right|
$$

and the Hamming and Euclidean metrics coincide [3]

Definition 2.3. In the case of the intuitionistic fuzzy sets these metrics are different [3] For an intuitionistic fuzzy set $A$ the Hamming metric is defined as; [3]

$$
h_{A}(x, y)=\frac{1}{2}\left(\left|\mu_{A}(x)-\mu_{A}(y)\right|+\left|\nu_{A}(x)-\nu_{A}(y)\right|\right)
$$

Definition 2.4. Let $X$ be nonempty. Intuitionistic fuzzy sets $A, B, C \in X$. The distance measure $d$ between intuitionistic fuzzy sets $A$ and $B$ is a mapping $d: X \times X \rightarrow[0,1]$; if $d(A, B)$ satisfies the following axioms:

A1) $0 \leq d(A, B) \leq 1$

A2) $d(A, B)$ if and only if $A=B$

A3) $d(A, B)=d(B, A)$

A4) $d(A, C)+d(B, C) \geq d(A, B)$ 
A5) if $A \subseteq B \subseteq C$, then $d(A, C) \geq d(A, B)$ and $d(A, C) \geq d(B, C)$

Distance measure is a term that describes the difference between intuiitonistic fuzzy sets and can be considered as a dual concept of similarity measure. Distance measures between intuitionistic fuzzy sets are proposed [4] [5].

Definition 2.5. Let $A=\left\{\left\langle x, \mu_{A}(x), \nu_{A}(x), \pi_{A}(x)\right\rangle \mid x \in X\right\}$ and $B=\left\{\left\langle x, \mu_{B}(x), \nu_{B}(x), \pi_{B}(x)\right\rangle \mid x \in X\right\}$ be two intuitionistic fuzzy sets in $X=x_{1}, x_{2}, \ldots, x_{n}, i=1,2, \ldots, n$. Based on the geometric interpretation of intuitionistic fuzzy set, Szmidt and Kacprzyk [4], [5] proposed the following four distance measures between $A$ and $B$ :

The Hamming distance;

$d_{H}(A, B)=\frac{1}{2} \sum_{i=1}^{n}\left(\left|\mu_{A}\left(x_{i}\right)-\mu_{B}\left(x_{i}\right)\right|+\left|\nu_{A}\left(x_{i}\right)-\nu_{B}\left(x_{i}\right)\right|+\left|\pi_{A}\left(x_{i}\right)-\pi_{B}\left(x_{i}\right)\right|\right)$

The Euclidean distance;

$d_{E}(A, B)=\sqrt{\frac{1}{2} \sum_{i=1}^{n}\left[\left(\mu_{A}\left(x_{i}\right)-\mu_{B}\left(x_{i}\right)\right)^{2}+\left(\nu_{A}\left(x_{i}\right)-\nu_{B}\left(x_{i}\right)\right)^{2}+\left(\pi_{A}\left(x_{i}\right)-\pi_{B}\left(x_{i}\right)\right)^{2}\right]}$

The Normalized Hamming distance;

$d_{n-H}(A, B)=\frac{1}{2 n} \sum_{i=1}^{n}\left(\left|\mu_{A}\left(x_{i}\right)-\mu_{B}\left(x_{i}\right)\right|+\left|\nu_{A}\left(x_{i}\right)-\nu_{B}\left(x_{i}\right)\right|+\left|\pi_{A}\left(x_{i}\right)-\pi_{B}\left(x_{i}\right)\right|\right)$

The Normalized Euclidean distance;

$d_{n-E}(A, B)=\sqrt{\frac{1}{2 n} \sum_{i=1}^{n}\left[\left(\mu_{A}\left(x_{i}\right)-\mu_{B}\left(x_{i}\right)\right)^{2}+\left(\nu_{A}\left(x_{i}\right)-\nu_{B}\left(x_{i}\right)\right)^{2}+\left(\pi_{A}\left(x_{i}\right)-\pi_{B}\left(x_{i}\right)\right)^{2}\right]}$

\section{School Determination Using The Intuitionistic Fuzzy Logic}

Let $H=\left\{H_{1}, H_{2}, H_{3}, H_{4}, H_{5}\right\}$ be a set of high schools,

$L=\{$ Turkish, Mathematics, Science, Social, English, Religion $\}$ be a set of lessons,

$P=\left\{P_{1}, P_{2}, P_{3}, P_{4}, P_{5}\right\}$ be a set of a student's pilot tests score.

Table 1 below has been calculated high school base point for each lesson in $L$.[14]

\begin{tabular}{|l|l|l|l|l|l|l|}
\hline & Turkish & Mathematics & Science & Social & English & Religion \\
\hline$H_{1}$ & $(0.965,0.028,0.007)$ & $(0.985,0.012,0.003)$ & $(0.995,0.004,0.001)$ & $(0.990,0.008,0.002)$ & $(0.975,0.020,0.005)$ & $(0.995,0.004,0.001)$ \\
\hline$H_{2}$ & $(0.910,0.080,0.010)$ & $(0.945,0.044,0.011)$ & $(0.945,0.044,0.011)$ & $(0.920,0.064,0.016)$ & $(0.900,0.080,0.020)$ & $(0.990,0.008,0.02)$ \\
\hline$H_{3}$ & $(0.845,0.124,0.031)$ & $(0.800,0.180,0.020)$ & $(0.825,0.140,0.035)$ & $(0.850,0.120,0.030)$ & $(0.855,0.126,0.019)$ & $(0.950,0.040,0.010)$ \\
\hline$H_{4}$ & $(0.710,0.261,0.029)$ & $(0.570,0.387,0.043)$ & $(0.750,0.200,0.050)$ & $(0.825,0.140,0.035)$ & $(0.650,0.280,0.070)$ & $(0.690,0.248,0.062)$ \\
\hline$H_{5}$ & $(0.640,0.324,0.036)$ & $(0.400,0.480,0.120)$ & $(0.550,0.405,0.045)$ & $(0.610,0.351,0.039)$ & $(0.570,0.345,0.085)$ & $(0.830,0.153,0.017)$ \\
\hline
\end{tabular}

Table 2 below has been determined depending on average of seven students' who were randomly selected pilot tests score.

\begin{tabular}{|l|l|l|l|l|l|l|}
\hline & Turkish & Mathematics & Science & Social & English & Religion \\
\hline$S_{1}$ & $(0.75,0.20,0.50)$ & $(0.765,0.20,0.035)$ & $(0.835,0.15,0.015)$ & $(0.84,0.13,0.03)$ & $(0.915,0.05,0.035)$ & $(0.925,0.05,0.025)$ \\
\hline$S_{2}$ & $(0.86,0.1,0.04)$ & $(0.83,0.15,0.02)$ & $(0.82,0.14,0.04)$ & $(0.89,0.1,0.01)$ & $(0.68,0.25,0.07)$ & $(0.89,0.09,0.02)$ \\
\hline$S_{3}$ & $(0.95,0.04,0.01)$ & $(0.975,0.02,0.005)$ & $(0.99,0.008,0.002)$ & $(0.99,0.008,0.002)$ & $(0.99,0.007,0.003)$ & $(0.98,0.015,0.005)$ \\
\hline$S_{4}$ & $(0.76,0.2,0.04)$ & $(0.59,0.36,0.05)$ & $(0.51,0.45,0.04)$ & $(0.68,0.24,0.08)$ & $(0.54,0.4,0.06)$ & $(0.89,0.09,0.02)$ \\
\hline$S_{5}$ & $(0.78,0.15,0.07)$ & $(0.65,0.25,0.10)$ & $(0.71,0.20,0.09)$ & $(0.65,0.30,0.05)$ & $(0.60,0.35,0.05)$ & $(0.92,0.06,0.02)$ \\
\hline$S_{6}$ & $(0.36,0.55,0.09)$ & $(0.35,0.6,0.05)$ & $(0.29,0.6,0.11)$ & $(0.375,0.5,0.125)$ & $(0.265,0.650,0.085)$ & $(0.4,0.5,0.1)$ \\
\hline$S_{7}$ & $(0.9,0.05,0.05)$ & $(0.95,0.03,0.02)$ & $(0.9,0.06,0.04)$ & $(0.95,0.01,0.04)$ & $(0.95,0.02,0.03)$ & $(0.95,0.05,0.00)$ \\
\hline
\end{tabular}


Table 3 below has been calculated shortest distance between each student (i.e.Table 2) and each high school (i.e. Table 1) using normalized hamming distance method depending upon average of students' pilot tests.

\begin{tabular}{|l|l|l|l|l|l|}
\hline & $H_{1}$ & $H_{2}$ & $H_{3}$ & $H_{4}$ & $H_{5}$ \\
\hline$S_{1}$ & 0.171 & 0.140 & 0.081 & 0.190 & 0.333 \\
\hline$S_{2}$ & 0.224 & 0.101 & 0.077 & 0.131 & 0.334 \\
\hline$S_{3}$ & 0.010 & 0.103 & 0.125 & 0.264 & 0.379 \\
\hline$S_{4}$ & 0.347 & 0.274 & 0.192 & 0.133 & 0.135 \\
\hline$S_{5}$ & 0.253 & 0.214 & 0.160 & 0.135 & 0.134 \\
\hline$S_{6}$ & 0.644 & 0.590 & 0.522 & 0.359 & 0.270 \\
\hline$S_{7}$ & 0.050 & 0.044 & 0.089 & 0.238 & 0.327 \\
\hline
\end{tabular}

Table 3 depicts that the shortest distance between each pilot test score and each high school has given. Depending upon Table 3 ; the student $S_{1}$ is to enroll in $H_{3}$ high school, the student $S_{2}$ is to enroll in $H_{3}$ high school, the student $S_{3}$ is to enroll in $H_{1}$ high school, the student $S_{4}$ is to enroll in $H_{4}$ high school, the student $S_{5}$ is to enroll in $H_{5}$ high school,the student $S_{6}$ is to enroll in $H_{5}$ high school,the student $\mathrm{S}_{7}$ is to enroll in $\mathrm{H}_{2}$ high school.

\section{Conclusion}

The relationship between the student's official test and the pilot test has been observed. This paper could applicable for each student.Factors affecting student achievement in official exam could be researched. This paper has been researched only through student's pilot tests because of factors such as capacity of student's working, student's psychology could be unknown exactly. This application of intuitionistic fuzzy set in high school determination is very useful; because by calculating distance between the student and each school, the most proper school for the student has been intuitionally determined.

In this paper; seven students who were randomly selected have been researched in order to form the above table. Moreover, this research can be applicable for all students. Socio-economic status and psychology of the students as well as success of schools, teacher role, order of preference and different city preference are ignored.Because these factors will have positive or negative effects on high school determination. As factors such as success of student, examination difficulty vary every year, these data will show variability for every year.This application of intuitionistic fuzzy set in high school determination is very useful; because by calculating distance between each student and each school, the most proper school for each student has been intuitionally determined.

Available system results with the method which we have used are compatible.This paper has shown that used method could be applied to evaluation system through various arrangements. This method is suitable in order to achieve more sensible results.Available evaluation system could be renewed by using intuitionistic fuzzy logic. Especially; using intuitionistic fuzzy logic will give very positive 
results in education system. In addition; success of teachers and students could be observed by means of intuitionistic fuzzy logic. Using an intuitionistic fuzzy logic based evaluation and determination system will have very beneficial results. This application will carry out a more accurate, more rational result that is make decisions or preferences without instant evaluation based on more stress-free, easier long term observation and determination.

\section{REFERENCES}

[1] L.A. Zadeh, Fuzzy Sets, Information and Control, 8, pp.338-353,(1965).

[2] K. Atanassov, Intuitionistic fuzzy sets, Fuzzy Sets and Systems, 20(1), pp.87-96,(1986).

[3] K. Atanassov, Intuitionistic Fuzzy Sets, Theory and Applications, Physica-Verlag Heidelberg, Germany,(1999).

[4] E. Szmidt and J. Kacprzyk, On Measuring Distances Between Intuitionistic Fuzzy Sets, Notes on IFS,3(4),pp.1-3,(1997).

[5] E. Szmidt and J.Kacprzyk, Distances Between Intuitionistic Fuzzy Sets, Fuzzy Sets and Systems, 114(3),pp. 505-518,(2000).

[6] E. Szmidt and J. Kacprzyk,Intuitionistic Fuzzy Sets in Some Medical Applications, Notes on IFS, 7(4), pp. 58-64,(2001).

[7] E. Szmidt and J. Kacprzyk,Medical Diagnostic Reasoning Using a Similarity Measure for Intuitionistic Fuzzy Sets, Notes on IFS, 10(4), pp. 61-69,(2004).

[8] Dr.G.Vasanti and T.Viswanadham, Intuitionistic Fuzzy Sets and Its Application in Student Performance Determination of a Course via Normalized Euclidean Distance Method,International Journal of Multidisciplinary and Scientific Emerging Research, Vol.4,No.1,(2015).

[9] P.A. Ejegwa, S.N.Chukwukelu and D.E.Odoh, Test of Accuracy of Some Distance Measures Use in the Application of Intuitionistic Fuzzy Sets in Medical Diagnosis, Journal of Global Research in Mathematical Archives,Vol.2, No.5, pp.55-60,(2014).

[10] P.A. Ejegwa, A.M.Onoja and I.T.Emmanuel, A Note Some Models of Intuitionistic Fuzzy Sets in Real Life Situations,Journal of Global Research in Mathematical Archives,Vol.2, No.5,pp.42-50,(2014).

[11] P.A.Ejegwa, A.J.Akubo and O.M.Joshua, Intuitionistic Fuzzy Sets and Its Application in Career Determination via Normalized Euclidean Distance Method, European Scientific Journal, Vol.10, No.15,(2014).

[12] P.A.Ejegwa, A.J.Akubo and O.M.Joshua.O.M.,Intuitionistic Fuzzy Sets in Career Determination, Global Journal of Science Frontier Research: F Mathematics and Decision Sciences, Vol.14, No.3,(2014).

[13] A.Kaufmann, Introduction to the theory of fuzzy sets, Academic Press, New York,(1975).

[14] F.Tuğrul, M.Gezercan and M. Çitil, Application of Intuitionistic Fuzzy Set in High School Determination Via Normalized Euclidean Distance Method, Notes on Intuitionistic Fuzzy Sets, Vol.23, No.1,pp.42-47(2017).

Department of Mathematics, Kahramanmaraş SÜtcü İmam University,Kahramanmaraş TURKEY

E-mail address: feridetugrul@gmail.com

Department of Mathematics, Kahramanmaraş SÜtcü İmam University,Kahramanmaraş TURKEY

E-mail address: citil@ksu.edu.tr

Kyrgyz-Turkish Manas University, BishKeK, Kyrgyzstan

E-mail address: balci@manas.edu.kg 